\title{
At the coalface, but on the receiving end
}

\author{
Peter Dewland and Jane Dewland Pentrecaeau Uchaf, Llandeilo Graban, Powys, Wales
}

\begin{abstract}
In dealing with patients the doctor is very often paternalistic. No more so than when the patient is unable to help him - or herself. Modern technology allows people to be kept alive in "intensive care" where they often become an "object" at the centre of proceedings. Fortunately for them, most patients who survive intensive care cannot remember the experience though this does not mean that they were not suffering at the time. There is a strong case for explaining things as much as possible and for making practical procedures as tolerable as possible.

The relatives and families of the seriously ill often have great difficulty in understanding what is happening to their loved ones and, in these situations, suffer a great deal of stress and foreboding regarding the ultimate outcome of their illness. The stress on the staff who may become "attached" to their patients often shows through as an indifferent attitude. Peter remembers three out of fourteen days in intensive care and Jane, his wife, remembers the whole experience. Here we tell our stories in the hope that they may help our medical and nursing colleagues to manage better the patients under their care in this situation
\end{abstract}

(Fournal of Medical Ethics 1999;25:541-546)

Keywords: Paternalism; intensive care

\section{Peter's story}

The worst days of my life were being fully conscious in an intensive care unit. But first, how did I get there and why this article?

I am a doctor. As a profession, we are extremely paternalistic. "There, it won't hurt" and "it will be a little bit painful but you will soon recover", are the sort of statements that occur in doctor-patient conversation every day. In most instances the physician, fortunately (or unfortunately), has not been on the "receiving end" and may thus be giving his reassurances in good faith. Living in a highly technological age means that virtually any procedure can be performed and so a patient may be kept alive under almost any circumstances. What that patient feels or suffers, both physically and psychologically, is poorly understood and poorly recorded. The very nature of the procedures involved in intensive care mean that the patient, who is often unconscious, may well lose his personal identity and just be regarded as a thing at the centrepiece of the proceedings. The patient's brain, having at some stage been anoxic, may play tricks on the patient so that his perception, when he returns to consciousness, may not be a realistic one; he may see or hear or read more into his surroundings than is actually the case. I want to describe the pain, mental anguish and frustrations of being on the receiving end of intensive care, as well as to give some thoughts on how the profession might approach this so that in future patients, aware of their surroundings might be treated more sympathetically.

It was a cold March day with a biting wind as I walked up a steep hill. As I was about half way up I began to develop a strange discomfort in my chest and my jaw. It was not a pain but a strange, constricting feeling. I stopped and sheltered in a doorway to find that it gradually eased off and within what seemed like five, but was probably only two minutes, I started on my way again. The sensation came on again; I knew what it was. It was described in every textbook of medicine and known as "chest pain on exertion". I had to stop three times before I got to the office where I saw a long queue of people waiting to see me. I could feel my anxiety levels rising as I performed my duties, rather more perfunctorily than usual. When we had finished my colleagues and I walked to our cars. Thankfully, the walk was downhill rather than up. I drove for home.

The road took me straight past the surgery and, after some considerable pleading with the receptionist, I was able to see one of the doctors. He immediately sent me for an electrocardiogram (ECG), and chest $x$-ray and then along home to rest with a glyceryl trinitrate (GTN) spray. I only needed the spray a couple of times that evening. The following day was a Saturday. I was looking forward to taking it easy and relaxing. That morning the telephone rang: it was the general 
practitioner (GP). He had looked at the ECG and chest $\mathrm{x}$-ray but couldn't see anything wrong with them. However, he had spoken to the local cardiologist who had insisted that I go into hospital for observation. Thus my bags were packed and I reported to the local District General Hospital.

\section{Sullen quietness}

Part of the anxiety I had felt until now revolved around the fact that I was pretty sure what was wrong with me and I was wondering how I was going to break this to my wife and family. As it happened, there really was little time because within a few hours of that telephone call I was in a hospital bed. I sat there imagining the panic and anxiety that this might have caused in my wife, my children, my parents, my in-laws and others I knew. Languishing in that bed in the male medical ward, induced a kind of sullen quietness in me. I didn't want to compare symptoms with my other inmates and, in fact, I didn't want to be there at all. It was curious to see one of my old colleagues from medical school conducting a ward round; he was shocked to see me sitting in a bed on his ward! I was extremely bored, and then the pain started again - only this time there was no exertion. After several thorough examinations they told me that I had a heart murmur (which I hadn't known before) but that it was thought that this was nothing to worry about. X-rays were taken, blood tests were performed and there was talk of a cardiac catheterisation. The pains got worse. They got more frequent and more severe. They began to wake me up at three o'clock in the morning.

I knew what this was; it was called "unstable angina". I knew what that meant; an impending heart attack! I was transferred to the university hospital, where I was placed in a bed in a small room of my own near to sister's office. A cardiac ultrasound was performed and I was told I had a slightly leaky valve, but nothing to worry about. A cardiac catheter was performed. My right coronary artery had a blockage and was filling in a retrograde fashion. The pain got worse and more frequent and every night I was waking up needing GTN for the pain. I became very anxious. After a week, I lost my temper with one of the medics who came to see me that evening. "If I need a bypass operation urgently, why haven't you done it?" Later that evening I was given a consent form and told that I was first on the list the following morning! The process of informed consent was undertaken by the most junior member of the medical team. "You're down for a CABG" he said in a rather perfunctory manner. I didn't know what "CABG" stood for. I eventually asked what was the risk. I was told $2 \%$ have complications and 1 don't make it. I signed.

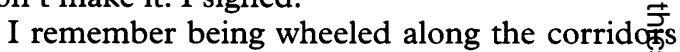
in a pre-medicated stupor and the pictures on the ceiling of the anaesthetic room. I got to the ust count of six or seven and that's the last I remeber.

The next thing I remember is blurred and fuztey and vague. There were four or five faces leanifg over and peering down at mine. They wewe dressed in operating theatre blues and particularly prominent were their blue hats and masks. I caret remember what they were saying. I think they were telling me not to worry, but it is a fleetiang memory, only a glimpse.

I still don't know the full story. I can only tibll you my memories. I have subsequently come :f learn that my wife, whose capacity for stress must have been almost infinite, knows the full story from a layman's point of view.

Up to now my memories have been lucid, but from here on they are disjointed and large piecos are missing.

\section{Uncomfortable tube}

I opened my eyes to see equipment surrounding me and to hear voices talking to me. I cant realise that these belonged to nurses and, in nmy mouth was a large, uncomfortable tube conneoted to a machine which was breathing for me. "Dot pull the tube, leave it alone Peter, please don't peyll it", "Get the anaesthetist, I think we'll have to gige him something". I realised I was thrashing round the bed and that this tube was making me gag, feel sick and salivate all at once. And how I wass wheezing. I had never wheezed before, why no $\overline{\mathbf{X}}$ ? As the nurses calmed me down I began to realise that I would have to accept this wretched tubes I would have to learn to cope with it. My wife, Jane, was there. How sweet to see her, to hold her hand, to see her smile as my eyes opened. Where ha\&I been and for how long? I had no idea. She spoke: I could not speak, it's that damned tube in rmy windpipe, my vocal cords are either side of 8 . Frustration again. "Would you mind leaving iึ, Mrs Dewland, for a few minutes?" said the kindty nurse. "Peter, we are going to suck you out". "Wke are going to put this small catheter down yours tube just to clear all the secretions and help yoyr breathing". Help my breathing! I am wheezing like hell and this machine's breathing for me, I caf $t$ fight it or breathe for myself, in fact if they turned it off I don't think I could breathe at all. Okay, lot them; I don't have any choice do I? The nurse piq her gloves on and takes a fine catheter out of cover, inserting it into the tube near my mough. The sheer convulsive pain of coughing apd 
coughing and retching and coughing through this awful tube. What is she doing? How can she do this? Must I go through this again? I stopped thrashing around the bed and lay back exhausted, realising that when the catheter touches your lungs it makes you cough like you never coughed before. Was this real life? Was it all a bad dream?

Sister came into my room. "Good morning Sister" said the nurses. "Hello Peter" she said, "How nice to see you awake. Now, we are going to sit you up, make you comfortable and we'll soon have that tube out and have you up on the ward." I wanted to say: "Sister, how nice to see you. How kind you and your staff are", but I couldn't. That damned tube, I couldn't say anything. Frustration. I seemed to have lots of visitors that day. My wife's sister somehow, uncannily, sensed my frustration. She disappeared; I thought she had gone. They sucked me out. She came back, bless her, she'd brought a secretary's writing pad and a pencil. A means of communication at last! "How are the kids" I wrote in a shaky, almost illegible hand. "Fine" said my wife. More visitors. Sucked out again; convulsive agony once more. Tired. Sleep and let machine do the breathing.

The visitors have gone. It's night and I have a new nurse; the incredibly painful coughing is much worse when she sucks me out.

\section{Irrationally anxious}

By now I have discovered the various tubes virtually everywhere. A cannula in each arm, three cannulas attached to my chest wall and an electric wire coming out of my chest. I subsequently realise one is a central venous cannula, one in my stomach for oral nutrition and medication and, to this day, I don't know where the third one went! A urinary catheter. A large endotracheal tube in my mouth. And an extremely sore backside! I hope she knows which of these tubes to put that crushed-up tablet in. I hope she has crushed it up properly. Why am I irrationally anxious? She must have done this hundreds of times. The previous nurse inspired confidence, this one doesn't. I have already filled half of the secretary's pad with written questions to the nurses and written statements. "I'm wheezing, I can't breathe, it's very difficult even with that machine, and it can't really push against the wheezing!" A nebulizer is placed in the tubing and drugs are placed in the nebulizer. Things are a little easier, but it doesn't make that much difference. I sleep, I wake up. That same nurse is there but she soon goes, to be replaced by an utterly delightful girl. She talks to me clearly and sympathises with me. She is calm and knows exactly what she is doing and how to wield that endotracheal catheter! "We'll get this tube out of you Peter," she says. "Now let's try you on a little bit of CPAP." It seems far worse than the other machine. I feel that I can't breathe at all.

But wait, what's that on the wall? It's weird, it's changing colour. It's psychedelic. Why is this happening? I do believe it is an hallucination. It fades, it's gone. I won't mention it, it's just my eyes playing tricks on me. "Now let's stop you wheezing, I'll get the doctor to have a look at you." More drugs in the nebulizer. In amongst this, the anaesthetist arrives. He talks to nurse, looks at me, goes away, but says nothing to me. He looks busy and pressurised. In the next room I hear them talking loudly to each other. I hear sloshing noises like buckets of ice. I hear shouts for warm packs. I think they are warming someone up after an operation? I wonder if they had to do that to me? More visitors. I write down to my wife that I don't feel so well today. She looks drawn, she's lost weight. My brother and mother arrive. All these people. Gosh I must have been ill; I don't understand. How long was I unconscious?

\section{More violent hallucinations}

I drift into sleep. I see visions on the wall, it's horrible. I descend beneath the road. We are on the Embankment, it's London, look at the traffic. These rats, they're huge, they are going to get me. I wake with a jolt. I drift again and colour becomes black and white and large and nondescript animals are coming to get me. This is most weird and most unpleasant. I can't tell the nurse; this damn tube. Here she comes with that catheter again. Now after we have sucked you out Peter, we are going to get you breathing on your own through this tube. I am going to sit here with you and I am going to help you with every breath". Now I have the fear of hallucinations and fear of the fact that they are going to turn the machine off and I won't be able to breathe. What if I can't breathe on my own? Will she see, will she notice, will she be capable of reconnecting me? I drift again. More violent hallucinations! I write on my pad, "Call the anaesthetist, please". It seems like an age, but eventually he arrives. The nurse points out to him that I feel rather agitated and I write on my pad that I am having frightening visual hallucinations of a terrifying type, and I point out that I have never had hallucinations before. The anaesthetist talks to me. "It must be some of the drugs we have had to give you to keep you on this machine. I don't think there is much we can do about it, but I am sure once these drugs wear off and you get breathing on your own everything will be fine". I will just have to keep awake, I can't let myself drift off. It's too horrendous. What if I was "an ordinary person"? How could I express to the 
anaesthetist that I was having "visual hallucinations"? I would just have to write down that I was "seeing things" I suppose.

My nurse is bullying me. "Come along now, breathe. In and out and in and out. You know it's three o'clock in the afternoon and I am going off at four thirty, I want you breathing on your own". She's a forceful woman. She'll make someone a good wife! She bullies me, but I know it's for my own good. I am breathing on my own through this tube. Somehow that just makes the being sucked out even more awful. I want to pull this damn tube out, I am fighting it all the time. "I am going to find the anaesthetist," she says. I hope I am all right, I hope I can breathe if she is not here. It seemed an interminable time; all sorts of thoughts went through my head so fast, so busy, so muddled. She comes back with the anaesthetist. "He has been doing well breathing on his own since $2 \mathrm{pm}$. I just thought you might like to come along and see him because I am not really sure whether he is ready to have it out". "OK, I'll be back soon". He turns on his heel. On the whole, I'm feeling much better. Nurse is still talking. She is off tonight for the weekend. "I'm going now". "Hello Peter". It's another of my favourite nurses on for the evening. "I hear you've been doing well all day. Breathing on your own eh? We'll soon have that tube out and get you up and about. It's really good news". They are so good, they're so kind, they're so enthusiastic and they really are treating me like a person, which is more than I can say for the medics. The consultant anaesthetist comes up to the side of the bed. "Well, you've done very well Peter, I think we can take that tube out."

\section{Weird sensation}

I feel him pulling around my face. "Now, I want you to take a big, deep breath and give a large cough" he tells me "and then I want you to take deep breaths on your own. Don't forget, with the shock of it all, to keep breathing! Now, a deep breath and a big cough." What a weird sensation. Ouch, it's really painful. It's all over in a second and it's out. I can see this huge tracheal tube in his hand. It looks absolutely vast. "There we are. Give a cough. Deep breath. Jolly good". He drops the tube on the floor, leaves the mess for nurse to clear up (as usual). It must have taken no more than two minutes from start to finish and, there I am, breathing, Yes, I really am breathing on my own, it's fantastic. This means no more suction catheters-hooray.

I want to talk to nurse, but I can't make a sound. Then I stop to think about it. That tube has been between my vocal cords for many days now, that's why I can't talk, the cords are sore and
I'm hoarse. "Don't worry" says nurse “your voide will come back, but it will take a good few days?. "OK", I think to myself and I keep writing on ng pad. I'm out of the woods, I'm on the way, bue?.I feel weak. But, I think I am going to sleep tonig I hope I keep breathing. Oh no, I've got no tubet. What if I can't breathe, they will have to intubefe me, I hope I'll be okay. The anxiety of it all probably engendered by the fact that I know to much about it! Jane will be pleased to see me when she comes. Here she is, look, no tube. I can't talk I've got to write, but what a pleasure. She can gife me a kiss for the first time. Oh my goodness, mouth tastes and feels horrible.

She tells me I had been unconscious for $11 \mathrm{dats}$ before I woke up. She tells me I bled into my chêst and had to go back to theatre 30 hours after the first operation. She tells me I had acute renal faidure. She doesn't tell me much else. Four years later and I still don't know the full story $8 \mathrm{r}$ remember most of it.

I was off work for six months in all. Now, fogr years later, with two new coronary arteries, a ne metal aortic valve and a completely different ou look on life, I have been signed off by the surgeots and cardiologists and am cared for by my GP. $\vec{\bullet}$

My wife got a peptic ulcer out of the deal, whises still causes her some trouble.

Was $I$, as a result of my training, more an than a layman would have been? I really worpy that, in intensive care, he would be realiy frightened, particularly as one is usually unpropared for such a situation.

The impersonal behaviour of the medie profession is nothing new, but I feel that they expressed their desire not to be emotionaty involved in the serious plight of the patient. To some extent this occurred with the nurses, who could not possibly cope if they were to identify with the patient - they lose too many for this to be tenable. The fact that the patient is unconsciogs leaves the physician with absolute power in terms of the patient's care and ultimate destiny-is this the ultimate in paternalism? Just telling the patieft what to expect and telling him what signs ad symptoms mean, would be an improvemengy! Talking to the relatives must be important. I waint

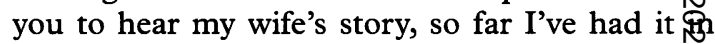
little pieces, not all together ...

\section{Jane's story}

I think I knew how ill Peter was about one monifh before. I had started taking our two boys out adl day on a Saturday so that Peter could relax (out $\bar{y}$ 9 am and back at $6 \mathrm{pm}$ ). Two kids, five years add two years old and three dogs, but at least Petgr looked better when I came home. 
When Peter rang me to pack a case and dump the kids on our friends, I was almost glad; at last he would rest!

He hated being in the local hospital. Peter is not a patient person; he calls a spade a spade and makes no small talk, so can you imagine what it was like for him in a room with five ex-miners. Conversation: racing, politics, pigeons and illness - he nearly went crazy. "Why are they sitting on me? Do something."

Two weeks (and me reversing into a neighbour's car) later, Peter had a new home, a room of his own in the university hospital. By this time he was asking for work to be brought in. His partner took it in. Medical students asking questions about Peter's illness and that of other people! Peter was happy again, teaching; being in charge.

$\mathrm{Me}$ ? I was still working full-time, relying on my mother and other friends to have the kids in the evening so that I could visit. One of the worst things is Alexander Bell's invention: the wretched telephone! It never stopped! People think they have a duty to ring every day. It's hard work to be nice at $11 \mathrm{pm}$ when you haven't eaten, or sat down all day.

1st April-great date for Peter's operation! My mother had a bypass when I was pregnant with our first child, so I thought I knew what to expect! I rang the ward at $8 \mathrm{am}$, Peter was ready to go down they said-give him my love I said and went off to work. I didn't know what else to do. I dropped Tom at the crèche, Nick in school and started my day. Nick was so excited, as he was taking part in a school concert that evening and his proud grandmother was going to watch. I rang at $4.30 \mathrm{pm}$ and was asked if I was going to come down to the hospital that evening. Well, the little booklet they give out to relatives of cardiac patients says do not visit the evening they have been in theatre so I asked: "Do you want me to?" "Yes" the voice said. I rang up my brother and asked him to stay with Tom whilst mum went to the concert with Nick. Very important-things must be normal.

\section{Two operations}

I arrived at the university hospital cardiac intensive care unit and was met by a doctor and nurse. We walked into a pretty, wall-papered, lounge-type room with sofas and magazines. I was told quickly how ill Peter was, how they had actually performed two operations at the same time on him, twice the time in theatre. I thought of the patients who didn't have their cardiac operations because of Peter. I wasn't listening to the doctor; I was looking at his mouth moving and his eyes-was Peter dead? No, nurse wasn't holding my hand as they had held my mother's hand when they told us daddy was dead. No: a good sign. Oh this doctor looked so tired. "Can I see him?" I found myself saying. "Yes, but there will be lots of tubes. Are you on your own?"

Peter looked hot when I saw him. The worst thing was a huge tube coming straight out of his chest and, on the floor, a big glass bottle, the type you buy cider in, filling up with Peter's blood. "What's that," I asked. "That's a problem," I was told by the doctor. "Peter is bleeding somewhere. We can't understand it and his chest is in very bad shape". I tell him that Peter had a very bad case of flu and chest infection two months ago. He nods and goes, walking slowly; how that man needed a bed himself? I sit there for a while, nurse tells me her name and what she is doing to Peter. All the time they talk to Peter, talking about what they are doing. They tell me to do the same.

I tell him I'm getting good at motorway driving. I ask the nurse what I should do now. She says to go home and sleep-what a laugh! At 7 am the next morning I ring the hospital and am told that Peter is not too well and was I going down? I race down. He is still bleeding. They are talking about opening Peter up again. I become worried and go home to see the kids; try and be normal, play cars, read books and phone and phone!

\section{Back to theatre}

People phone. What should I say? "He's fine". "No, by the way keep Friday free for Peter's possible funeral". No, keep positive Jane, tell them the truth. The funny thing was that the phone calls became fewer.

People say "Jane's a brick; tower of strength". True, I didn't cry outwardly, but many a time in a lay-by. Peter's temperature was going up and I stayed by his bed on and off until $11 \mathrm{pm}$, when a fussy, bossy nurse told me to go home. I pointed out how far away I lived, but she said not to worry there would not be any change until the morning. I decided to stay with my brother who lived 24 miles away from the hospital.

The phone went at approximately 2 am. It was the nice nurse. "Peter is going back to theatre now, he's not well". I drop the phone, dress, go out to the car and drive. I did the journey in fifteen minutes, passing two lots of police cars along the way. I must have looked as though I was not going to stop. Get to the hospital, porters let me in, run up the stairs and into ICU just to see Peter gowned-up with blue matching hat, give him a kiss and he's wheeled away.

I was placed in another room-no lounge-like sofa here-cold hard seats. The window has been left open and all around me are posters of children 
and people whose lives have been saved by donor cards. So this is how they do it! Even with your eyes closed you can feel those smiling faces looking at you. No, if I can't have him, no one can. Two hours later I start to read some of their stories, about children especially. Just like our boys. A cup of weak tea arrives with a male nurse. Did I want him to ring family for me? "No, I'm fine", I said. He goes. I want my dad, that's all. I hear crying outside and screaming. I later find out that a child has died in another room.

At 6 am a nurse comes in and says Peter's back. I thank God and go to see him. He looks better. A stitch around his heart valve had been missed and that was why his chest was filling up with blood. Tube gone. Nurse says you can hire a room here. I do, and find the chapel. In the next two to three weeks when I wasn't sitting by Peter, talking or reading to him or racing home to see the children, at least once a day I was in the chapel thinking about all our plans and praying. "Please God, do what's right for Peter".

I lost a stone in weight and became hardened. Peter's family came only once to see him. My family were there every night for a while. But now I had a new family. We were the relatives of the very sick. All different backgrounds and ages, but something in common: a loved one seriously ill. There was one family from a very rough neighbourhood who kept me going. Every time one of them went for a meal they would drag me along. We talked all the time about our lives. There was another man whose son had been in a road traffic accident and was very ill (head injury-pressure kept going up). He used to go to the chapel with me in the early hours of the morning and cry. He blamed himself, and told me how his best friend had been killed whilst he had been driving 15 years ago. Another young lad - he and his brother had been in care all their lives - was dying. We all helped to arrange his funeral. New faces came and went on "surgery days", but these people were not part of our "family". We had secrets anymore and we cried for each other, it whs unreal.

Ten days passed. Would today be the day Pefer would wake up? Open his eyes? At home $\overrightarrow{\text { fy }}$ mother kept strong for the kids and good frients helped her. A long time later an older friend $f$ f ours (thirty years of being a soldier) told us hồ he broke down when Nick asked him if daddy was going to die and go to heaven.

What had been going through that five-year-old head? We will never really know.

Then he opened his eyes! They were grey, red and watery-I loved them.

He looked so frightened. This was "in charge Peter, who knew the names of all the machirios which they were using on him. It was Derby Doy and the nurses brought in a television for Petercio watch. I rang the family and cried with my other family. You see, I was starting to lose theon, because my loved one was getting better.

Peter couldn't talk and slept a lot. My sister gå him a pad to write notes on. He loved this, but tबidd us about "bad dreams". I thought it must be le "cold turkey"-he got through this.

In the ten days Peter slept, things went wrod $\overrightarrow{0}$ along the way. His kidneys started to failo became diabetic. One day, one of the doterys stopped me and said that his main line neof d changing and they may have to do a tracheotong I went home to bath my boys.

When Peter was very ill I was talking to his coli sultant very late in the evening and I suddenly said to him: "Go home to your family or you will $\$$ e next". The nurse was shocked. Nobody talks like that to a consultant. He just smiled and said.ర్త్ $\mathrm{I}$ know".

Peter Dewland, BSc, MA, MBBS, FFPM, DCP \$ is a Specialist in Pharmaceutical Medicine. Fane Dewland is a working mother of two sons. 